Research Article

\title{
Low-Abundance Dietzia Inhabiting a Water-Flooding Oil Reservoir and the Application Potential for Oil Recovery
}

\author{
Peike Gao $\mathbb{D},{ }^{1}$ Hongbo Wang, ${ }^{2}$ Guanxi Li, ${ }^{1}$ and Ting Ma $\mathbb{D}^{3}$ \\ ${ }^{1}$ College of Life Sciences, Qufu Normal University, Qufu, Shandong 273165, China \\ ${ }^{2}$ Research Institute of Experimental Detection, Xinjiang Oilfield Company, Petro China, Karamay, Xinjiang 834000, China \\ ${ }^{3}$ College of Life Sciences, Nankai University, Tianjin 300071, China
}

Correspondence should be addressed to Peike Gao; gpkyll-001@163.com and Ting Ma; tingma@nankai.edu.cn

Received 23 April 2019; Revised 7 August 2019; Accepted 16 August 2019; Published 2 October 2019

Academic Editor: Aparup Das

Copyright (C) 2019 Peike Gao et al. This is an open access article distributed under the Creative Commons Attribution License, which permits unrestricted use, distribution, and reproduction in any medium, provided the original work is properly cited.

With the development of molecular ecology, increasing low-abundance microbial populations were detected in oil reservoirs. However, our knowledge about the oil recovery potential of these populations is lacking. In this study, the oil recovery potential of low-abundance Dietzia that accounts for less than $0.5 \%$ in microbial communities of a water-flooding oil reservoir was investigated. On the one hand, Dietzia sp. strain ZQ-4 was isolated from the water-flooding reservoir, and the oil recovery potential was evaluated from the perspective of metabolisms and oil-displacing test. On the other hand, the strain has alkane hydroxylase genes alkB and P450 CYP153 and can degrade hydrocarbons and produce surfactants. The core-flooding test indicated that displacing fluid with $2 \%$ ZQ-4 fermentation broth increased $18.82 \%$ oil displacement efficiency, and in situ fermentation of ZQ-4 increased $1.97 \%$ oil displacement efficiency. Furthermore, the responses of Dietzia in the reservoir accompanied by the nutrient stimulation process was investigated and showed that Dietzia in some oil production wells significantly increased in the initial phase of nutrient injection and sharply decreased along with the continuous nutrient injection. Overall, this study indicates that Dietzia sp. strain has application potential for enhancing oil recovery through an ex situ way, yet the ability of oil recovery in situ based on nutrient injection is limited.

\section{Introduction}

Oil reservoirs harbor diverse microbial populations that contribute to oil exploitation [1-3]. Among them, hydrocarbon-degrading bacteria are one of the most widely studied populations because of their important roles in the microbial enhanced oil recovery (MEOR) process. These microorganisms are generally able to produce surfactants with crude oil as a sole carbon source [4-6]. The produced surfactants can lower oil viscosity and oil-water interfacial tension to improve the recovery of residual oil underground. The products of oil oxidation, including fatty acids and surface-active agents, can serve as metabolic substrates for fermentative and methanogenic microorganisms that can produce fatty acids, alcohols, and gas. The metabolites improve oil recovery via reservoir repressurization, oil swelling, and decrease of oil viscosity [7].
Over the decades, many researchers devoted to isolate hydrocarbon-degrading bacteria from oil reservoirs and to investigate how these microorganisms improve oil recovery [5, 8-14]. To date, the isolated hydrocarbon-degrading microorganisms mainly belong to Pseudomonas [15-17], Acinetobacter [5], Bacillus [8, 18], Aeribacillus pallidus [19], Bacillus licheniformis [20], and Geobacillus [21]. These microbial populations were demonstrated to be able to enhance oil recovery in laboratory, and some species were found showing positive responses with incremental oil in laboratory and MEOR field trials [5, 8, 9, 22, 23].

With the development of molecular ecology, in particular, 16S rRNA high-throughput sequencing, more and more low-abundance microbial populations have been detected in oil reservoirs. Our previous investigation indicated that low-abundance Dietzia was generally detected in oil reservoirs, including 22 reservoirs with distinct different 
formation temperatures and salinity, across North, Northeast, and Northwest of China [24]. In addition, several Dietzia strains have been isolated from oil reservoirs and were found able to utilize hydrocarbons [25-27]. However, despite that, our knowledge about the oil recovery potential of these low-abundance microbial populations is poor. In this study, the distribution of Dietzia inhabiting a waterflooding oil reservoir was investigated. A Dietzia sp. strain ZQ-4 was isolated from the water-flooding reservoir, and the oil recovery potential was evaluated from the perspective of metabolisms and oil-displacing test. In addition, the responses of Dietzia in the reservoir accompanied by a nutrient stimulation process were investigated. The results will benefit our understanding about the roles of low-abundance Dietzia in the MEOR process.

\section{Materials and Methods}

2.1. Reservoir Information. The oil reservoir is located in Karamary Oilfield, Northwest China, has been subjected to water flooding since 2001. The temperature of the oilbearing strata is $39^{\circ} \mathrm{C}$, with a formation pressure of 14.71 MPa. The density of the crude oil is $0.862 \mathrm{~g} \cdot \mathrm{cm}^{-3}$, with a viscosity of $60.5 \mathrm{mPa} \cdot \mathrm{s}$. MEOR based on nutrient injection through water injection wells was performed in the reservoir. The nutrients consist of molasses, $\left(\mathrm{NH}_{4}\right)_{2} \mathrm{HPO}_{4}$, and $\mathrm{NaNO}_{3}$. The production brines were collected from wellheads of the oil production wells through sampling valves and then completely filled in $15 \mathrm{~L}$ sterile plastic bottles and sealed with screw caps to avoid contamination and oxygen intrusion.

2.2. Microbial Community 16S rRNA Gene Sequencing. Total genomic DNA of microbial communities in the production brines was extracted using a bead shaker treatment and the AxyPrep ${ }^{\mathrm{TM}}$ Genomic DNA Miniprep Kit, Axygen, USA [22]. Universal primers 515f (GTG CCA GCM GCC GCG GTAA) and 806r (GGA CTA CHV GGG TWT CTA AT) were used to amplify the $16 \mathrm{~S}$ rRNA V4 region (300-350 bp) according to the protocol described by Caporaso et al. $[28,29]$. The PCR reaction mixture contained $10.5 \mu \mathrm{L}$ sterile $\mathrm{ddH}_{2} \mathrm{O}, 4 \mu \mathrm{L} 5 \times$ TransStart ${ }^{\circledR} \mathrm{FastPfu}$ Buffer (TransGen Biotech, China), $2 \mu \mathrm{L} 2.5 \mathrm{mM}$ dNTPs, $0.5 \mu \mathrm{l}$ TransStart ${ }^{\circledR}$ FastPfu DNA Polymerase, $0.5 \mu \mathrm{L}$ forward primer $(10 \mu \mathrm{M}), 0.5 \mu \mathrm{L}$ reverse primer $(10 \mu \mathrm{M})$, and $2 \mu \mathrm{L}$ sample DNA. The reaction systems were denatured for $2 \mathrm{~min}$ at $95^{\circ} \mathrm{C}$ followed by 25 cycles at $94^{\circ} \mathrm{C}$ for $30 \mathrm{~s}, 50^{\circ} \mathrm{C}$ for $30 \mathrm{~s}, 72^{\circ} \mathrm{C}$ for $30 \mathrm{~s}$, and a final elongation step at $72^{\circ} \mathrm{C}$ for $5 \mathrm{~min}$. Amplicons were sequenced by pair-end sequencing on an Illumina MiSeq platform at Beijing Novogene Co. The raw sequences from sequencing were processed using Quantitative Insights into Microbial Ecology (QIIME) software package [30, 31]. Pairs of reads were merged using fast length adjustment of short reads (FLASH) [32]. The obtained sequences were demultiplexed and quality filtered using QIIME. The sequences were clustered into operational taxonomic units (OTUs) based on a threshold of $97 \%$ for sequence identity using UCLUST [33].
2.3. Isolation and Identification of Dietzia Strains. To isolate hydrocarbon-degrading Dietzia strains, $20 \mathrm{~mL}$ production brines were inoculated into $80 \mathrm{~mL}$ sterile basal salts medium (BSM) with $0.5 \%$ crude oil obtained from the oil production wells, and then, it was inoculated at $39^{\circ} \mathrm{C}$ and $180 \mathrm{rpm}$ for 5 days. The BSM medium contained $\mathrm{Na}_{2} \mathrm{HPO}_{4}(0.6 \mathrm{~g} / \mathrm{L})$, $\mathrm{KH}_{2} \mathrm{PO}_{4}(0.2 \mathrm{~g} / \mathrm{L}), \mathrm{NaNO}_{3}(4 \mathrm{~g} / \mathrm{L}), \mathrm{CaCl}_{2}(0.01 \mathrm{~g} / \mathrm{L}), \mathrm{FeSO}_{4}$ $(0.01 \mathrm{~g} / \mathrm{L}), \mathrm{MgSO}_{4}(0.3 \mathrm{~g} / \mathrm{L})$, and yeast extract $(0.01 \mathrm{~g} / \mathrm{L})$, with $\mathrm{pH}$ equal to the production brines (7.5). Aliquots of $10^{-3}$ to $10^{-5}$ dilutions of the enrichment culture in which oil was emulsified were plated onto crude oil agar BSM and then incubated at $39^{\circ} \mathrm{C}$ until single colony formation.

The genome of the isolated strains was extracted with AxyPrep $^{\text {тм }}$ Genomic DNA Miniprep Kit (Axygen, USA). Microbial 16S rRNA genes were amplified using universal primers $27 \mathrm{f}\left(5^{\prime}\right.$-AGA GTT TGA TCT GGC TCA G-3') and 1492r (5'-TAC GGT TAC CTT GTT ACGACTT-3') [34]. The obtained 16S rRNA amplicons were sequenced and compared with sequences deposited in the GenBank database to find the most closely related populations. Alkane monooxygenase (alkB) and cytochrome P450 (CYP 153) genes that are related to oil degradation were detected with degenerate primers. The alkBwf $5^{\prime}$-AAY CAN GCN CAY GAR CTN GGV CAY AA- $3^{\prime}$ and alkBwr $5^{\prime}$-GCR TGR TGR TCH GAR TGN CGY TG-3' were used to detect the alkB gene, producing approximately $550 \mathrm{bp}$ amplicons $[35,36]$. Primers P450F $\left(5^{\prime}\right.$-TGT CGG TTG AAA TGT TCA TYG CNM TGG AYC C-3') and P450R (5'-TGC AGT TCG GCA AGG CGG TTD CCS RYR CAV CKR TG-3') were used to amplify $\mathrm{P} 450$ genes, producing approximately $800 \mathrm{bp}$ amplicons [35, 37]. Phylogenetic trees were constructed in MEGA 4 using the neighbor-joining method [38, 39]. The $16 \mathrm{~S}$ rRNA gene and hydrocarbon-degrading gene sequences were deposited in GenBank databases under accession numbers JQ809512, MF188901, and MF188902, respectively.

\subsection{Determination of Microbial Growth and Surfactant} Production. The growth and surfactant production of the isolated Dietzia strain when growing on BSM with glucose, glycerol, bean oil, molasses, corn steep powder, and hydrocarbons as a sole carbon source were investigated. The growth curves were measured based on CFU (colony forming unit) counts: plating aliquots of samples on Luria-Bertani (LB) agar plates that were incubated at $39^{\circ} \mathrm{C}$ for 3 days. $\mathrm{pH}$ of the fermentation broths was measured by the $\mathrm{pH}$ test strip. Surface tension of the fermentation brines was measured using a digital tension meter (POWEREACH JK99B, China) at room temperature. The produced surfactants were separated from the culture medium by a solvent extraction method. After separation of biomass, the $\mathrm{pH}$ of the supernatant was adjusted to 2 with $6 \mathrm{M} \mathrm{HCl}$ and then extracted three times with an equal volume of chloroform/methanol $(\mathrm{v} / \mathrm{v}, 2: 1)$ in a separating funnel. The solvent layer was evaporated under vacuum to obtain extracts. The obtained extracts were ground with $\mathrm{KBr}$ powder and were dispersed uniformly in a matrix of paraffin for Fourier-transform infrared (FTIR) spectrometry measurement in the frequency range of $4,000-500 \mathrm{~cm}^{-1}$. 


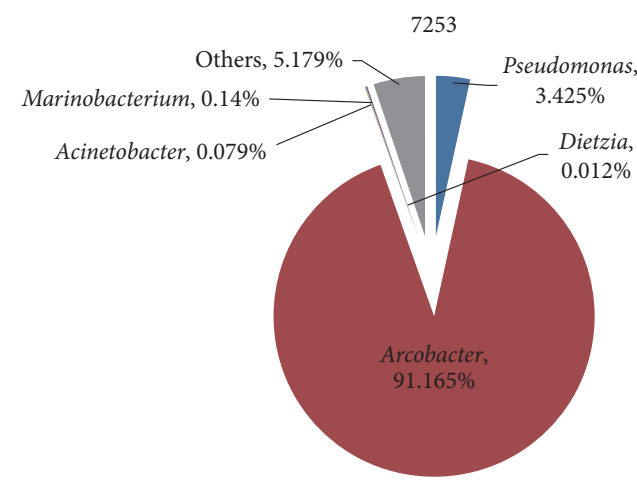

(a)

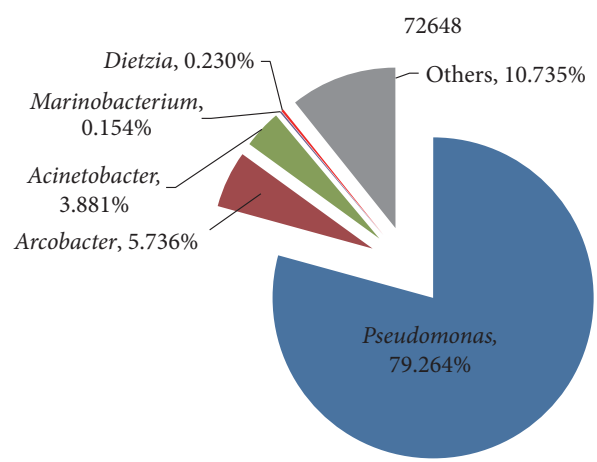

(c)

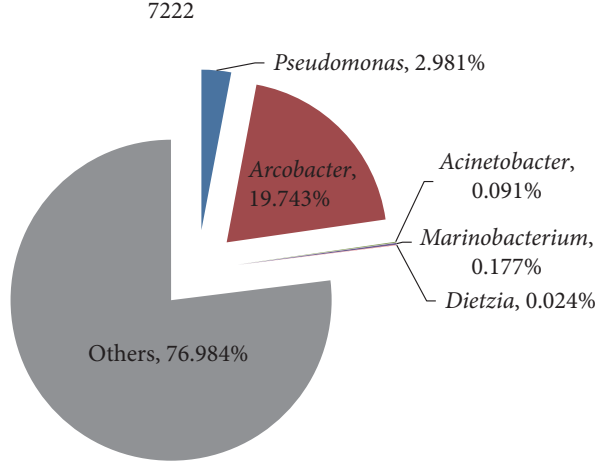

(b)

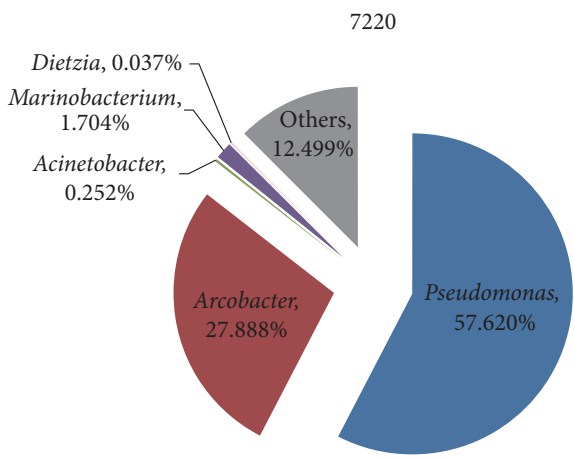

(d)

Figure 1: Distribution of dominant microbial populations and Dietzia in oil production wells (a) 7253, (b) 7222, (c) 72648, and (d) 7220.

2.5. Determination of Oil Emulsification and Degradation. The oil emulsification and degradation ability of the isolated Dietzia strain were evaluated on BSM with $0.5 \%$ crude oil as a sole carbon source in aerobic, anoxic, and anaerobic conditions. Anoxic cultivation was accomplished by sealing an Erlenmeyer flask with a rubber stopper. Anaerobic cultivation was carried out in $300 \mathrm{~mL}$ serum bottles containing $200 \mathrm{~mL}$ medium and $0.1 \%$ resazurin. The serum bottles were then flushed with $\mathrm{N}_{2}$ flowed by sealing with a rubber stopper. The inoculated strain was harvested from precultures in the LB medium by centrifugation at $10,000 \times g$ for $5 \mathrm{~min}$ and then washed twice with sterile BSM to exclude the residual organic compounds. Oil emulsion was evaluated based on the produced oil droplets using an optical microscopy with microscopic image analysis software, which yielded the average, maximum, and minimum diameters of the oil droplets. The residual crude oil was extracted with chloroform and then was separated into saturated hydrocarbons, aromatic hydrocarbons, asphaltene, and nonhydrocarbon fractions in a silica gel G column (60-120 mesh, $30 \mathrm{~cm} \times 2 \mathrm{~cm}$ i.d.). The saturated hydrocarbons were analyzed by gas chromatography on Agilent 7890 equipped with the HP5MS capillary columns $(60 \mathrm{~m} \times 0.25 \mathrm{~mm}$ i.d., $0.25 \mathrm{~mm}$ thickness).

2.6. Determination of Oil Displacement Efficiency in Cores. The oil recovery potential of isolated Dietzia strain was evaluated in rock cores. The core models were $29.5-29.8 \mathrm{~cm}$ in length and $2.1 \mathrm{~cm}$ in diameter, with pore percentages of
$25.25-26.51 \%$ and water permeability of $0.517-0.601 \mu \mathrm{m}^{2}$. To evaluate the ex situ oil recovery potential of the isolated Dietzia strain, the oil-bearing cores were first water flooded until no oil was displaced out, and then, formation brines with 2\% Dietzia sp. ZQ-4 fermentation liquor were injected into the core until no more oil was observed in the effluent. The control using the BSM medium containing $0.2 \%$ glycerol instead of fermentation liquor was performed in the same condition. To evaluate the in situ oil recovery potential of the isolated Dietzia strain, the oil-bearing core was first flooded by sterile formation brines with or without Dietzia sp. ZQ-4 (10 7 cells $/ \mathrm{ml}$ ) until no oil was displaced out; then, 0.2 pore volume nutrient medium $\left(0.6 \% \mathrm{NaNO}_{3}, 0.2 \%\left(\mathrm{NH}_{4}\right)_{2} \mathrm{HPO}_{4}\right.$, and $0.2 \%$ glycerol) prepared by production brines was injected into the cores. The cores were sealed and then incubated at $39^{\circ} \mathrm{C}$ for 7 days, followed by water flooding again until no further oil was obtained. Oil recovery efficiency and water content were calculated according to the volumes of displaced oil and displaced water in the core-flooding process.

\section{Results and Discussion}

3.1. Relative Abundances of Dietzia in the Oil Reservoir. Microbial communities in oil production wells of the oil reservoir were analyzed by $16 \mathrm{~S}$ rRNA sequencing. Phylogenetic analysis showed that the dominant microbial populations belonged to Proteobacteria, Firmicutes, Actinobacteria, Bacteroidetes, Thermotogae, and Synergistetes. At the genus level, Pseudomonas, Arcobacter, Acinetobacter, 


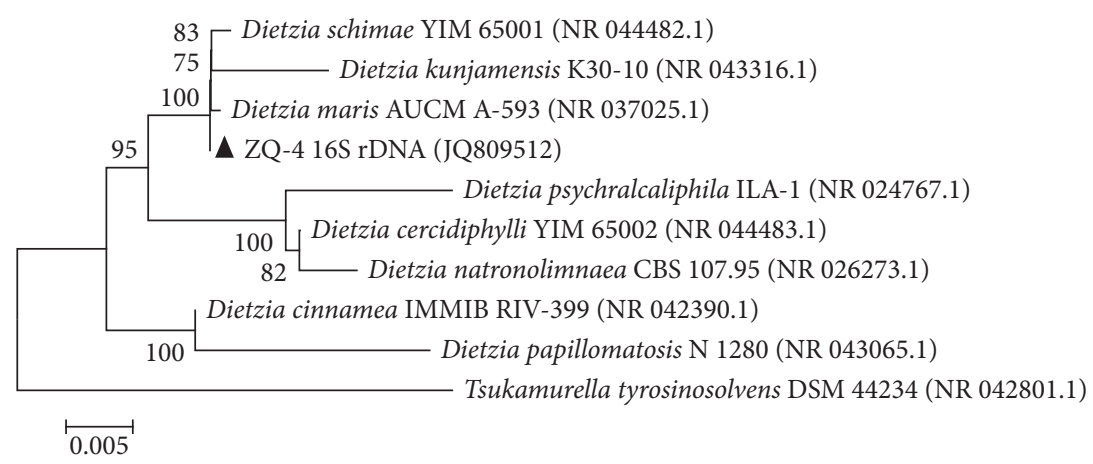

(a)

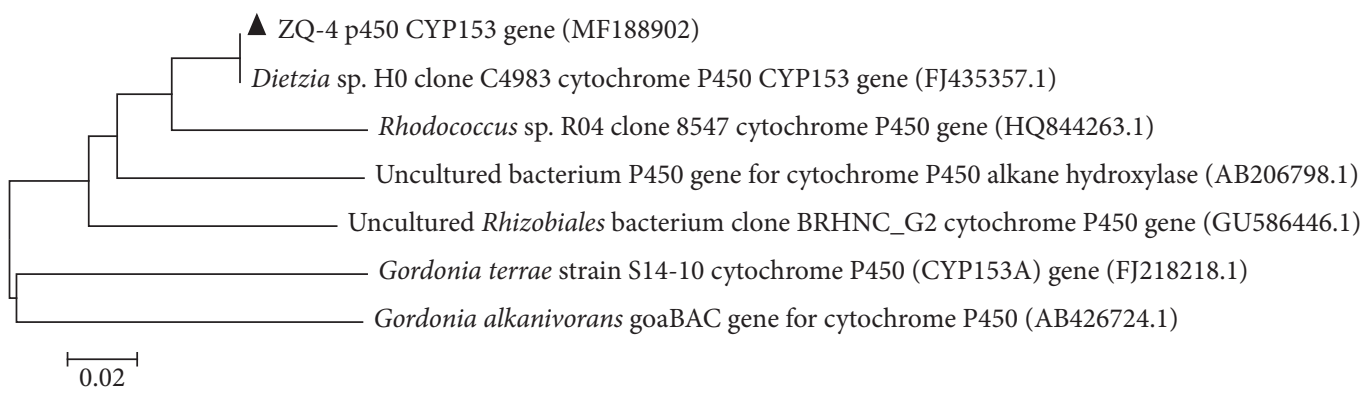

(b)

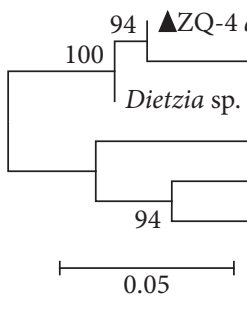

Dietzia sp. K44 alkane hydroxylase gene (AY819733.1)

H0 alkane-1 monooxygenase (alkB) gene (FJ435354.1)

Dietzia sp. H0B alkane-1 monooxygenase (alkB) gene (FJ435355.1)

Dietzia sp. E1transporter, alkane hydroxylase/rubredoxin fusion protein (FJ744758.1)

- Dietzia sp. DQ12-45-1b AlkB/rubredoxin fusion protein gene (HQ850583.1)

(c)

Figure 2: Phylogenetic relationships between Dietzia ZQ-4 and related species based on sequences of 16S rRNA gene (a), alkB gene (b), and CYP 153 gene (c).

and Marinobacterium were the most frequently detected populations (Figure 1). Although Dietzia is a kind of obligate aerobes, it was generally detected in the oil production wells, with its relative abundances of less than $0.5 \%$ (Figure 1). Our previous study also indicated that low-abundance Dietzia generally inhabited Chinese oil reservoirs [24]. Recently, Akbari et al. demonstrated that a nonmotile hydrocarbondegrading Dietzia maris could migrate in submicrometer pores and low-permeability media [40]. In that case, Dietzia that inhabits oil reservoirs may be collected by flooding fluids from different habitats through oil-bearing strata.

3.2. Characterization of Dietzia sp. ZQ-4. Recently, several Dietzia strains have been isolated from oil reservoirs [2527]. Despite the low abundance, Dietzia sp. ZQ-4 that could emulsify crude oil was isolated from the production brines. It showed $99 \%$ similarity of $16 \mathrm{~S}$ rRNA gene with Dietzia maris gene (Figure 2(a)). Alkane monooxygenase alkB and cytochrome P450 (CYP 153) genes were detected in the strain (Figures 2(b) and 2(c)), indicating the potential for hydrocarbon degradation.
After ZQ-4 treatment in aerobic conditions, oil emulsion formed with an average oil droplet diameter of $4.7 \mu \mathrm{m}(97 \%$ $<10 \mu \mathrm{m}$ ) (Figure 3(a)), saturated hydrocarbons of the crude oil decreased from $66.24 \pm 0.74 \%$ to $55.64 \pm 1.14 \%$, and aromatic hydrocarbons increased from $14.50 \pm 0.69 \%$ to $18.65 \pm 0.53 \%$ (Table 1). GC analysis showed that ZQ-4 preferentially degraded $n$-alkanes ranging from $\mathrm{C}_{14}$ to $\mathrm{C}_{33}$ (Figure 4(a)). There were also research studies showing that Dietzia strains with alkB and CYP 153 genes could utilize $\mathrm{C}_{6}$ to $\mathrm{C}_{40}[26,41,42]$. Microemulsions formed with an average oil droplet diameter of $12 \mu \mathrm{m}(97 \%<23 \mu \mathrm{m})$ after ZQ-4 treatment in anoxic conditions $\left(\mathrm{V}_{\text {liquid }} / \mathrm{V}_{\text {air }}=1 / 2\right.$ ) (Figure $3(\mathrm{~b})$ ), and the saturated hydrocarbon decreased from $65.80 \pm 1.01 \%$ to $56.96 \pm 0.81 \%$ (Table 1 ). Oil degradation and emulsification were not obviously observed in anaerobic conditions (Figure 4(c) and Table 1). Although a previous study reported that Dietzia maris CBMAI 705 was able to degrade phenanthrene and methylphenanthrenes [43], aromatic hydrocarbon degradation by ZQ-4 were not obviously observed (Table 1). The hydrocarbon-degrading ability makes Dietzia be able to survive with crude oil as a sole carbon source in oil reservoir environments. 

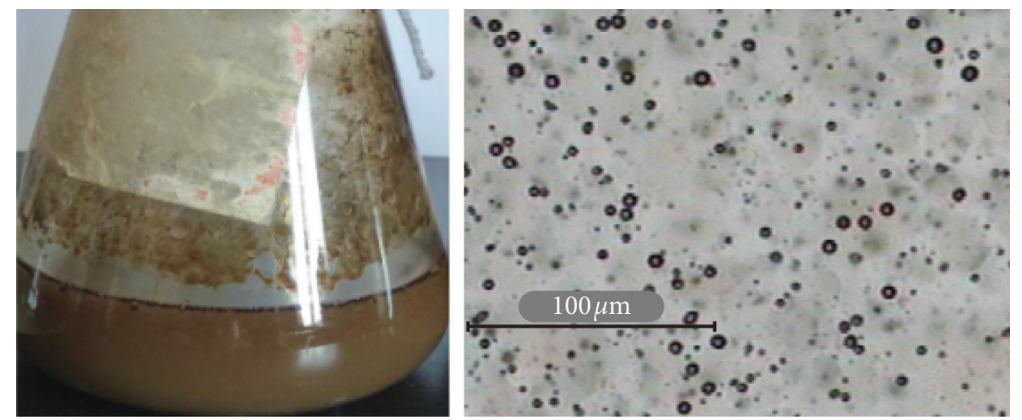

(a)
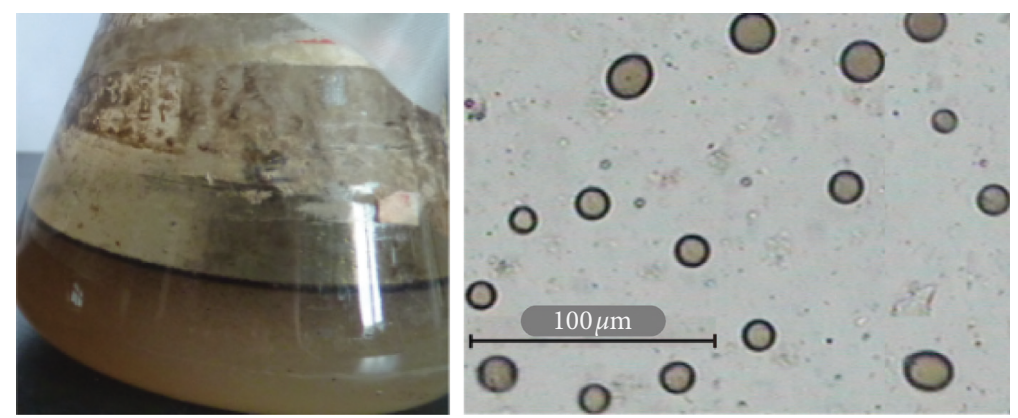

(b)

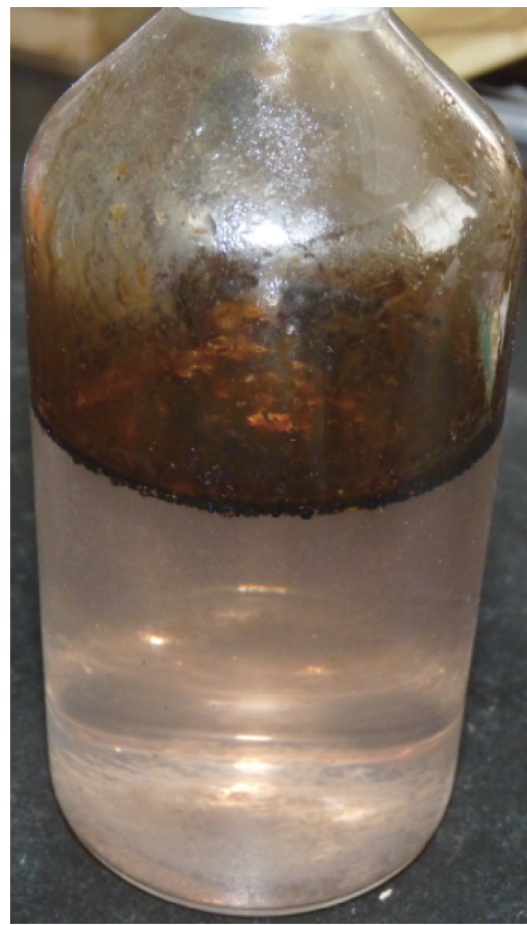

(c)

FIgURE 3: Oil emulsification by Dietzia ZQ-4 in aerobic condition (a), limited air supply condition with an air-liquid ratio of $2: 1$ (b), and anaerobic condition (c).

TABLE 1: Relative contents of saturated hydrocarbon and aromatic hydrocarbon in crude oil before and after ZQ-4 treatment.

\begin{tabular}{|c|c|c|}
\hline Experiment groups & Saturated hydrocarbon (\%) & Aromatic hydrocarbon (\%) \\
\hline \multicolumn{3}{|c|}{ Oil degradation in aerobic condition } \\
\hline Control & $66.24 \pm 0.74$ & $14.50 \pm 0.69$ \\
\hline 3 days & $55.64 \pm 1.14$ & $18.65 \pm 0.53$ \\
\hline \multirow{2}{*}{\multicolumn{3}{|c|}{$\begin{array}{l}\text { Oil degradation in limited oxygen supply condition } \\
\left(\mathrm{V}_{\text {air }} / \mathrm{V}_{\text {liquid }} 2: 1\right)\end{array}$}} \\
\hline & & \\
\hline Control & $65.80 \pm 1.01$ & $13.05 \pm 1.01$ \\
\hline 60 days & $56.96 \pm 0.81$ & $16.72 \pm 0.61$ \\
\hline \multicolumn{3}{|c|}{ Oil degradation in anaerobic condition } \\
\hline Control & $65.39 \pm 1.01$ & $16.76 \pm 1.02$ \\
\hline 60 days & $64.84 \pm 0.73$ & $16.88 \pm 0.26$ \\
\hline
\end{tabular}

Biosurfactants were considered to be a critical role in a MEOR process. Biosurfactants can effectively improve the sweep efficiency of oil-bearing rocks to recover the residual oil underground through decreasing oil viscosity and interfacial tension of oil-water [2, 3, 44]. Strain ZQ-4 was found to be able to produce surfactants in BSM with glycerol, corn steep powder, vegetable oil, and hydrocarbons as a carbon source, respectively (Figure 5). As a result of the surfactant production, the surface tension of the culture was reduced to $32 \mathrm{mN} / \mathrm{m}$. Infrared spectrogram showed that the produced surfactant with glycerol and $n$-hexadecane as a sole carbon source had the NH group $\left(3330 \mathrm{~cm}^{-1}\right), \mathrm{CH}_{3}$ group $\left(2925 \mathrm{~cm}^{-1}\right.$ and $\left.1434 \mathrm{~cm}^{-1}\right), \mathrm{CH}_{2}$ group $\left(2850 \mathrm{~cm}^{-1}\right.$ and $\left.1380 \mathrm{~cm}^{-1}\right)$, $\mathrm{CONH}_{2}$ group $\left(1548 \mathrm{~cm}^{-1}\right), \mathrm{CN}$ group $\left(1548 \mathrm{~cm}^{-1}\right)$, and lactone group $\left(1171 \mathrm{~cm}^{-1}\right.$ and $\left.1731 \mathrm{~cm}^{-1}\right)$, indicating that the produced surfactant contains lipopeptides (Figure 5(c)).
3.3. Oil Displacement Efficiency of Dietzia sp. ZQ-4 in Cores. Figure 6(a) shows the oil recovery and water ratio in the core-flooding process and revealed the oil displacement efficiency of ZQ-4 fermentation liquor. A large number of research studies have reported the oil recovery potential of Bacillus subtilis, Bacillus licheniformis, Pseudomonas aeruginosa, Rhodococcus erythropolis, and Thermoanaerobacter [18, 45-49]. These strains and their metabolites were found to be able to enhance oil recovery by $4.89-31 \%$ in the coreflooding test. In this study, displacing fluid with $2 \%$ ZQ-4 fermentation broth could significantly increase oil displacement efficiency $(18.82 \%)$ in cores, showing the oil recovery potential. The in situ fermentation of ZQ-4 in cores was also performed to evaluate the in situ oil displacement efficiency of ZQ-4. As shown in Figure 6(b), ZQ-4 in situ fermentation increased $1.97 \%$ oil displacement efficiency. 

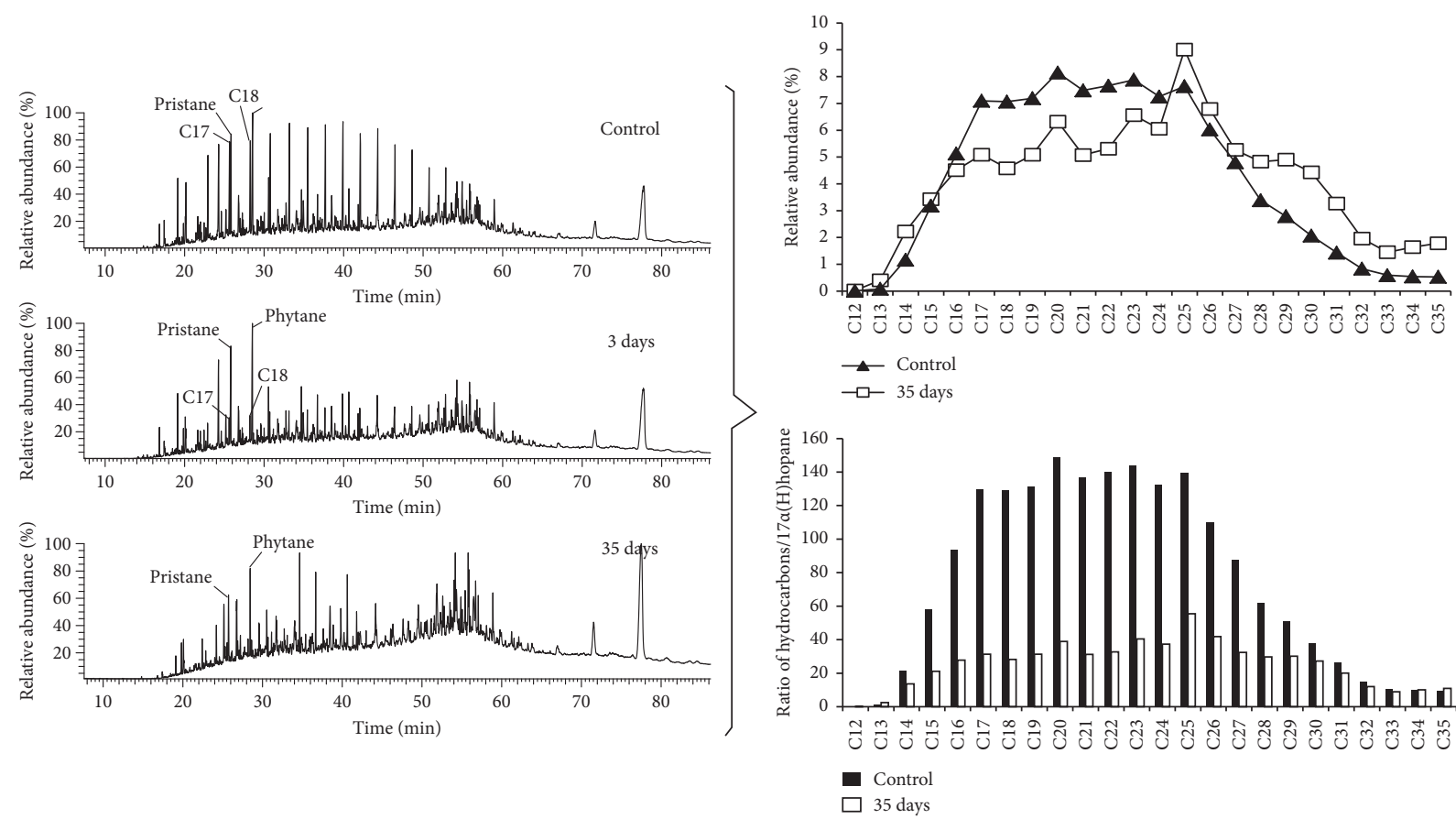

(a)
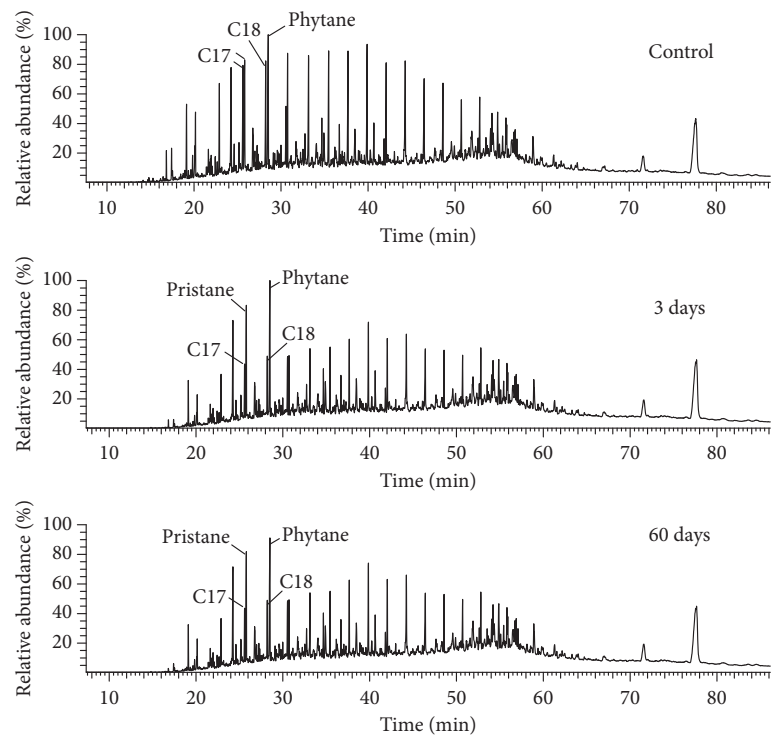

(b)
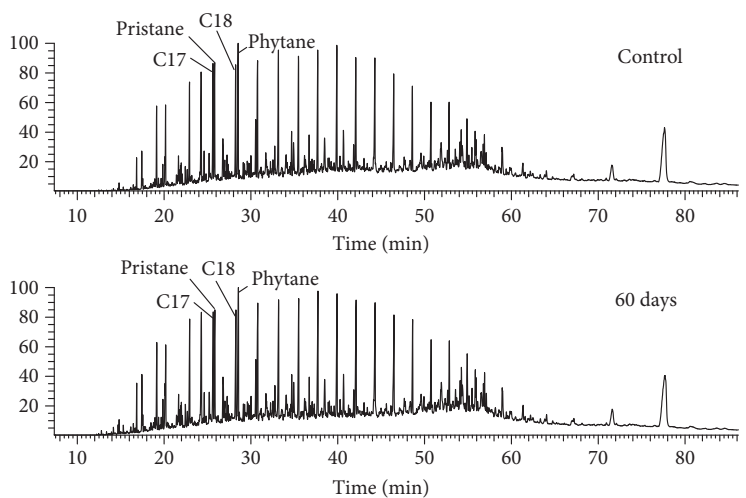

(c)

FIGURE 4: Gas chromatograms and relative proportions of different chain-length hydrocarbons in crude oil before and after Dietzia ZQ-4 treatment in aerobic condition (a), limited air supply condition (b), and anaerobic condition (c). 


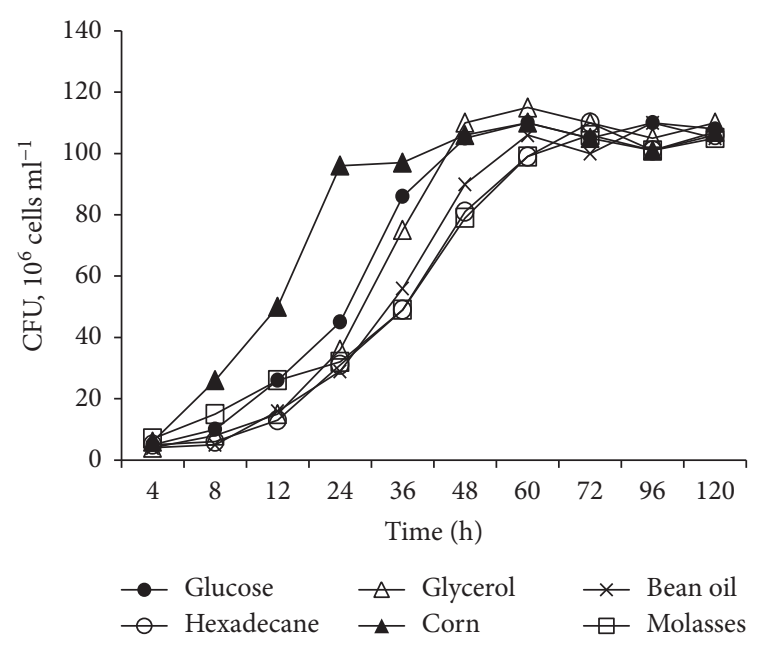

(a)

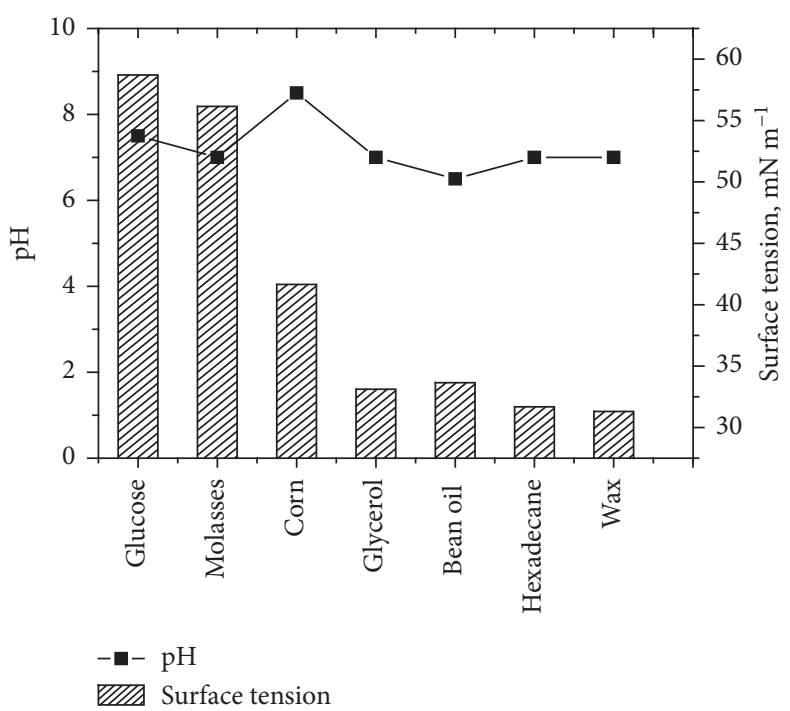

(b)

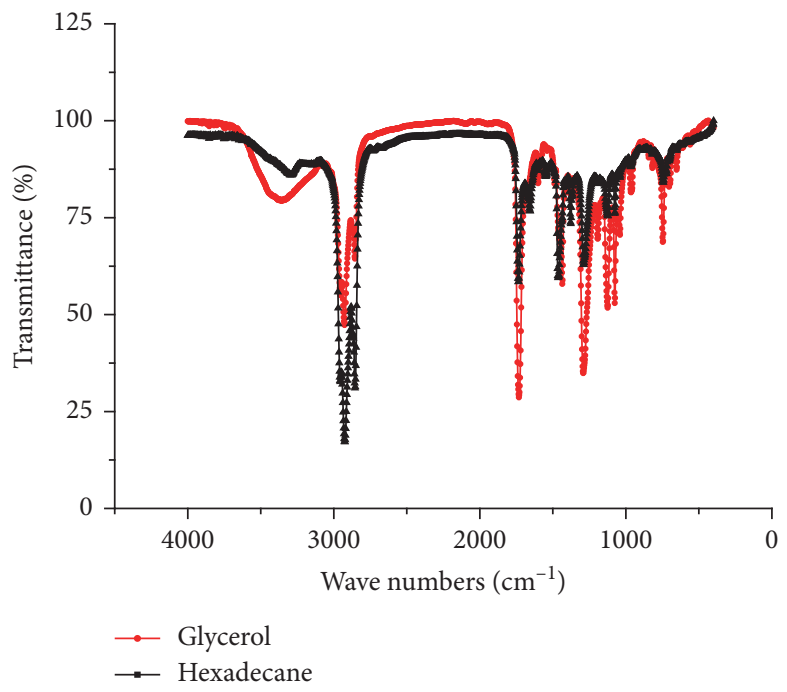

(c)

Figure 5: Growth of Dietzia ZQ-4 on BSM with different carbon sources as a sole carbon source (a), surface tensions of the fermentation broths (b), and infrared spectrogram of the produced surfactants with glycerol and $n$-hexadecane as a sole carbon source (c).

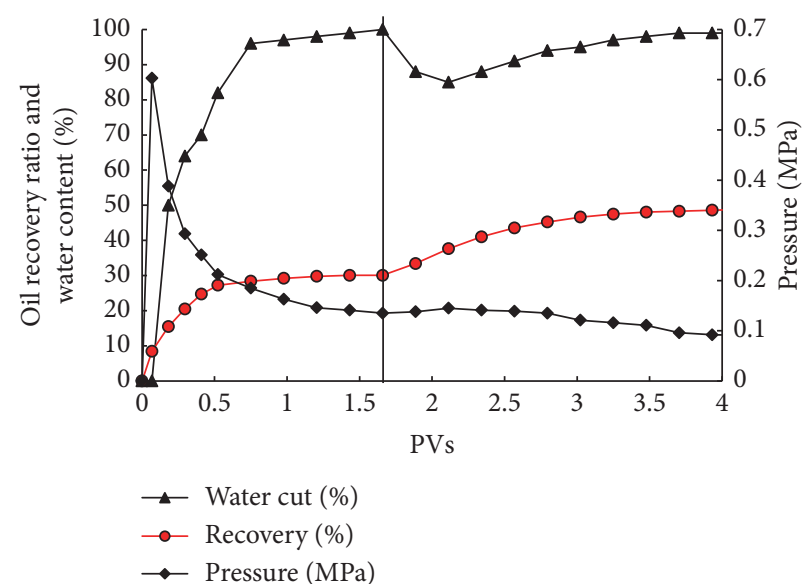

(a)

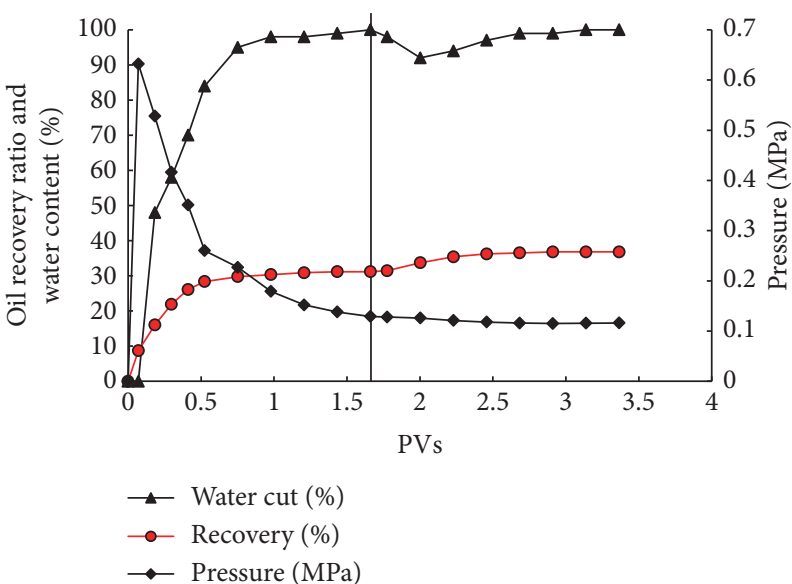

(b)

Figure 6: The water ratio, oil recovery ratio, and injection pressure during core-flooding tests: (a) ex situ oil recovery potential of Dietzia sp. ZQ-4 in core test; (b) in situ oil recovery potential of ZQ-4 in the core test accompanied by a nutrient stimulation process. The vertical bars in (a) and (b) indicate the injection of formation brines with fermentation liquor of ZQ-4 and nutrient injection, respectively. 

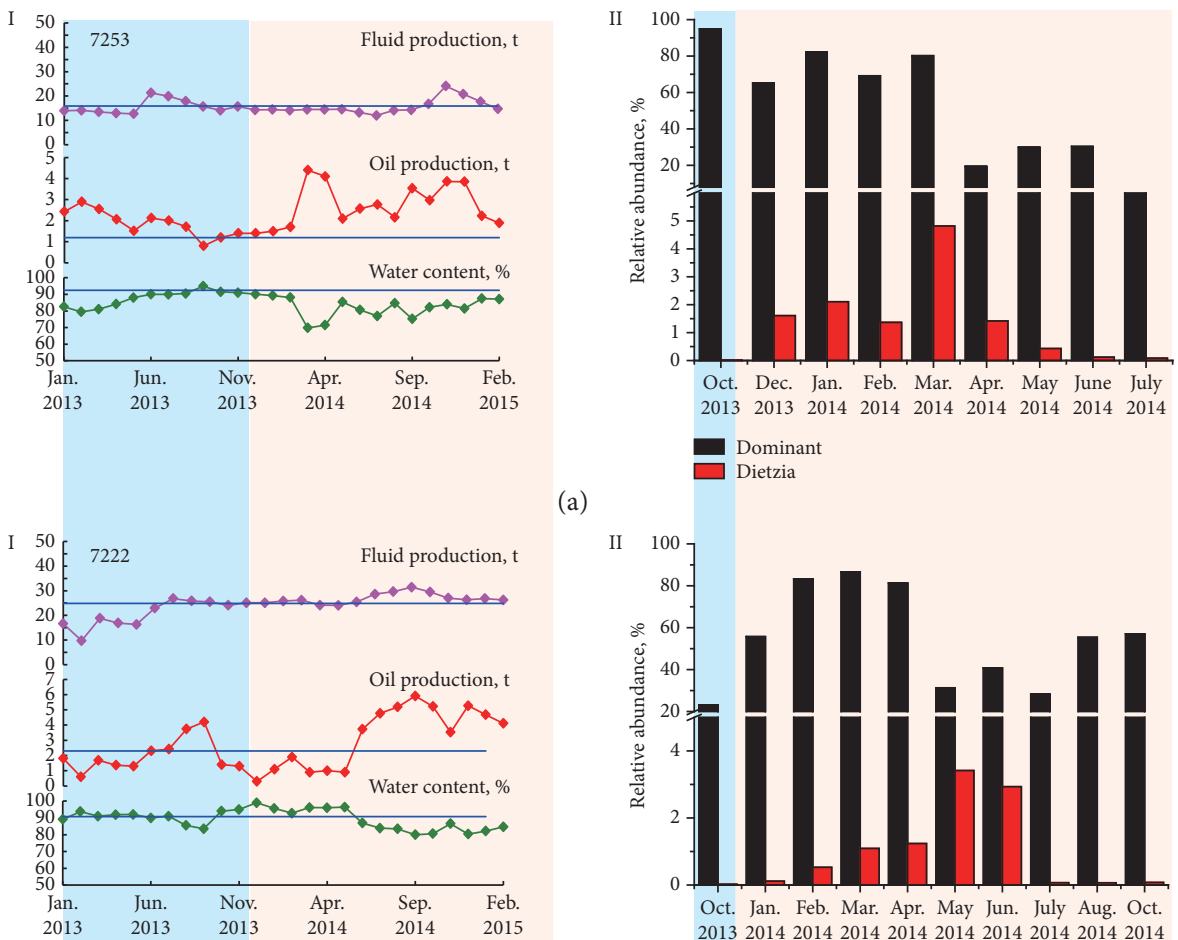

(a)

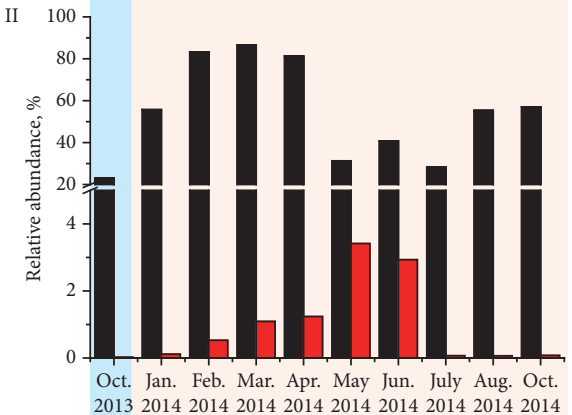

(b)
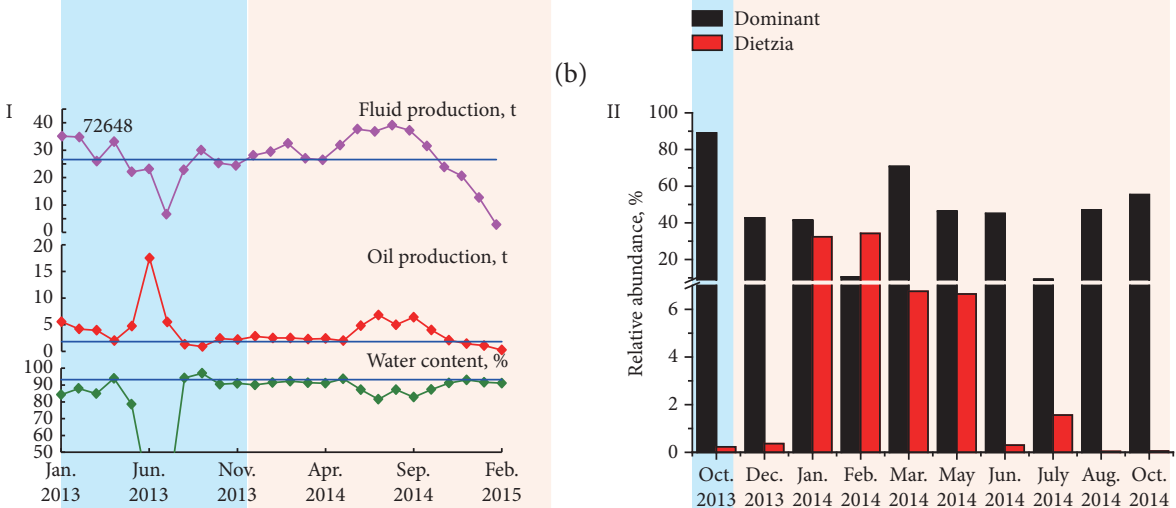

(c)

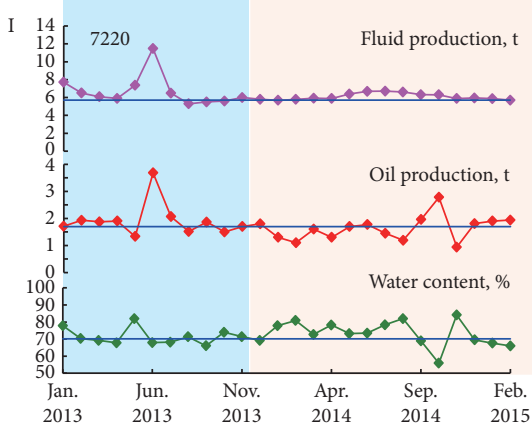

$$
\square \text { Dietzia }
$$

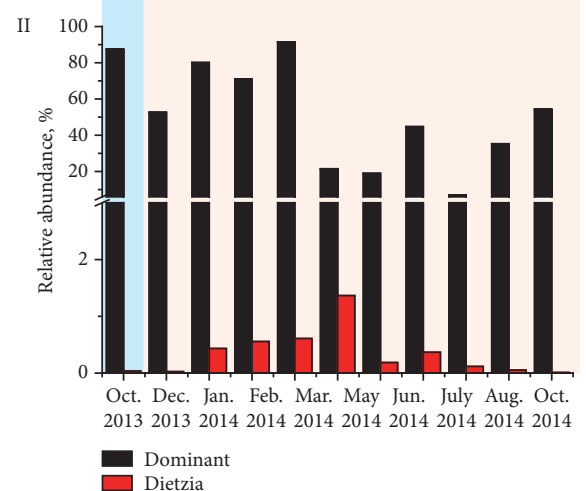

(d)

FIGURE 7: Oil production performances (I) and changes of dominant microbial populations (II) in the oil production wells 7253 (a), 7222 (b), 72648 (c), and 7220 (d) in the nutrient injection process. In part II, the dominant populations refer to Pseudomonas, Arcobacter, Acinetobacter, and Marinobacterium. 
The results indicate that ZQ-4 has the application potential in MEOR through an ex situ way, yet it is hard to improve oil recovery in situ based on nutrient solution injection. Combined with the above results, the limited dissolved oxygen in injected aerated nutrient solution is apparently the crucial constraint, which determines whether ZQ-4 can massively grow and produce sufficient surfactants to improve oil recovery in the hypoxic environment.

3.4. Responses of Dietzia in the Reservoir in the Nutrient Injection Process. Community analysis showed that Pseudomonas, Arcobacter, Acinetobacter, and Dietzia significantly increased in the oil production wells when aerated nutrient solution was injected into the reservoir trough injection wells (Figure 7), indicating that Dietzia grew in oil-bearing strata. Our previous MEOR field trial in a low-temperature reservoir has also found that some undetected microbial populations, such as Dietzia, Shewanella, Rhizobium, and Rhodococcus, clearly increased during the nutrient injection process, yet the relative abundances of these microbial populations were less than $1 \%$ in the communities at a concentration of $10^{7}-10^{8}$ cells $\mathrm{mL}^{-1}$ [22]. According to the production curves, the oil production wells were classified into two groups. For production wells 7253 and 7222, the liquid yield did not obviously change, whereas the oil production increased and water content decreased (Figures 7(a) and 7(b)). For production wells 72648 and 7220, oil increment and water content did not show obvious differences during the nutrient injection process (Figures $7(\mathrm{c})$ and $7(\mathrm{~d})$ ). Although incremental oil was obtained from production wells 7253 and 7222, it is hard to assess the contributions of the increased microbial populations, in particular Dietzia. For instance, Pseudomonas, Arcobacter, Acinetobacter, and Dietzia predominated production wells 72648 and 7220 during the nutrient injection process, yet there was no obvious oil increment (Figures $7(\mathrm{c})$ and $7(\mathrm{~d})$ ). In addition, with the continuous nutrient injection, Dietzia significantly decreased in the above oil production wells, in which Pseudomonas, Arcobacter, and Acinetobacter still predominated.

\section{Conclusions}

This study investigated the ex situ and in situ oil recovery potential of low-abundance Dietzia that inhabits a waterflooding oil reservoir. A Dietzia sp. ZQ-4 with the ability of hydrocarbon degradation and surfactant production was isolated, and the oil recovery potential was evaluated from the perspective of metabolisms and oil-displacing test. The results showed that displacing fluid with $2 \%$ ZQ-4 fermentation broth could significantly increase oil displacement efficiency in the core-flooding test, whereas in situ fermentation of ZQ-4 increased $1.97 \%$ oil displacement efficiency. Field trials with nutrient injection showed that Dietzia significantly increased in some oil production wells after nutrient injection yet sharply decreased along with continuous nutrient injection. Collectively, the results benefit our understanding about the roles of low-abundance Dietzia in the MEOR process: Dietzia can enhance oil recovery through an ex situ way and is limited to in situ oil recovery based on nutrient injection.

\section{Data Availability}

The data used to support the findings of this study are included within the article. The original data related to this study are available from the corresponding author upon request.

\section{Conflicts of Interest}

Hongbo Wang was employed by PetroChina Xinjiang Oilfield Limited Company. All authors declare that there are no conflicts of interest.

\section{Authors' Contributions}

Peike Gao and Ting Ma conceived and designed the experiments. Peike Gao and Hongbo Wang performed the experiments and analyzed the data. Peike Gao wrote the manuscript. All authors have reviewed the final version of the manuscript. All authors made contributions to the conception and design of the study, the drafting of the article, and the final approval of the submitted version.

\section{Acknowledgments}

This work was supported by the National Natural Science Foundation of China (Grant no. 31500414), Natural Science Foundation of Tianjin (Grant no. 16JCYBJC23700), and Natural Science Foundation of Jiangsu (Grant no. BK20151278).

\section{References}

[1] M. Magot, B. Ollivier, and B. K. C. Patel, "Microbiology of petroleum reservoirs," Antonie Van Leeuwenhoek, vol. 77, no. 2, pp. 103-116, 2000.

[2] N. Youssef, M. S. Elshahed, and M. J. McInerney, "Chapter 6 microbial processes in oil fields," Advances in Applied Microbiology, vol. 66, pp. 141-251, 2009.

[3] G. Voordouw, "Production-related petroleum microbiology: progress and prospects," Current Opinion in Biotechnology, vol. 22, no. 3, pp. 401-405, 2011.

[4] W. Xia, Z. Du, Q. Cui et al., "Biosurfactant produced by novel Pseudomonas sp. WJ6 with biodegradation of n-alkanes and polycyclic aromatic hydrocarbons," Journal of Hazardous Materials, vol. 276, pp. 489-498, 2014.

[5] H. Dong, W. Xia, H. Dong et al., "Rhamnolipids produced by indigenous Acinetobacter junii from petroleum reservoir and its potential in enhanced oil recovery," Frontiers in Microbiology, vol. 7, no. 1710, 2016.

[6] X.-B. Wang, Y. Nie, Y.-Q. Tang, G. Wu, and X.-L. Wu, "n -alkane chain length Alters Dietzia sp. strain DQ12-45-1b biosurfactant production and cell surface activity," Applied and Environmental Microbiology, vol. 79, no. 1, pp. 400-402, 2013.

[7] M. V. Ivanov, S. S. Belyaev, I. A. Borzenkov, I. F. Glumov, and R. R. Ibatullin, "Additional oil production during field trials in Russia," Developments in Petroleum Science, vol. 39, pp. 373381, 1993.

[8] N. Youssef, D. R. Simpson, M. J. McInerney, and K. E. Duncan, "In-situ lipopeptide biosurfactant production 
by Bacillus strains correlates with improved oil recovery in two oil wells approaching their economic limit of production," International Biodeterioration \& Biodegradation, vol. 81, pp. 127-132, 2013.

[9] Z. Y. Song, H. Y. Han, and W. Y. Zhu, "Morphological variation and recovery mechanism of residual crude oil by bio-surfactant from indigenous bacteria: macro- and porescale experimental investigations," Journal of Microbiology and Biotechnology, vol. 25, no. 6, pp. 918-929, 2015.

[10] G. Castorena-Cortés, T. Roldán-Carrillo, J. Reyes-Avila, I. Zapata-Peñasco, M. Mayol-Castillo, and P. Olguín-Lora, "Coreflood assay using extremophile microorganisms for recovery of heavy oil in Mexican oil fields," Journal of Bioscience and Bioengineering, vol. 114, no. 4, pp. 440-445, 2012.

[11] P. Sarafzadeh, A. Niazi, V. Oboodi et al., "Investigating the efficiency of MEOR processes using Enterobacter cloacae and Bacillus stearothermophilus SUCPM\#14 (biosurfactant-producing strains) in carbonated reservoirs," Journal of Petroleum Science and Engineering, vol. 113, pp. 46-53, 2014.

[12] G. Castorena-Cortés, I. Zapata-Peñasco, T. Roldán-Carrillo et al., "Evaluation of indigenous anaerobic microorganisms from Mexican carbonate reservoirs with potential MEOR application," Journal of Petroleum Science and Engineering, vol. 81, pp. 86-93, 2012.

[13] M. Xiao, Z.-Z. Zhang, J.-X. Wang et al., "Bacterial community diversity in a low-permeability oil reservoir and its potential for enhancing oil recovery," Bioresource Technology, vol. 147, pp. 110-116, 2013.

[14] J. Lin, B. Hao, G. Cao et al., "A study on the microbial community structure in oil reservoirs developed by water flooding," Journal of Petroleum Science and Engineering, vol. 122, pp. 354-359, 2014.

[15] X. Liang, R. Shi, M. Radosevich et al., “Anaerobic lipopeptide biosurfactant production by an engineered bacterial strain for in situ microbial enhanced oil recovery," RSC Advances, vol. 7, no. 33, pp. 20667-20676, 2017.

[16] F. Zhao, R. Shi, Q. Cui, S. Han, H. Dong, and Y. Zhang, "Biosurfactant production under diverse conditions by two kinds of biosurfactant-producing bacteria for microbial enhanced oil recovery," Journal of Petroleum Science and Engineering, vol. 157, pp. 124-130, 2017.

[17] F. Zhao, J. Zhou, S. Han, F. Ma, Y. Zhang, and J. Zhang, "Medium factors on anaerobic production of rhamnolipids by Pseudomonas aeruginosa SG and a simplifying medium for in situ microbial enhanced oil recovery applications," World Journal of Microbiology and Biotechnology, vol. 32, no. 4, p. 54, 2016.

[18] J. F. B. Pereira, E. J. Gudiña, R. Costa et al., "Optimization and characterization of biosurfactant production by Bacillus subtilis isolates towards microbial enhanced oil recovery applications," Fuel, vol. 111, no. 9, pp. 259-268, 2013.

[19] A. B. Poltaraus, D. S. Sokolova, D. S. Grouzdev et al., "Draft genome sequence of Aeribacillus pallidus strain $8 \mathrm{~m} 3$, a thermophilic hydrocarbon-oxidizing bacterium isolated from the dagang oil field (China)," Genome Announcements, vol. 4, no. 3, 2016.

[20] N. Aurepatipan, V. Champreda, P. Kanokratana, T. Chitov, and S. Bovonsombut, "Assessment of bacterial communities and activities of thermotolerant enzymes produced by bacteria indigenous to oil-bearing sandstone cores for potential application in Enhanced Oil Recovery," Journal of Petroleum Science and Engineering, vol. 163, pp. 295-302, 2018.

[21] M. Fulazzaky, D. I. Astuti, and M. A. Fulazzaky, "Laboratory simulation of microbial enhanced oil recovery using
Geobacillus toebii R-32639 isolated from the Handil reservoir,” RSC Advances, vol. 5, no. 5, pp. 3908-3916, 2015.

[22] G. Li, P. Gao, Y. Wu et al., "Microbial abundance and community composition influence production performance in a low-temperature petroleum reservoir," Environmental Science \& Technology, vol. 48, no. 9, pp. 5336-5344, 2014.

[23] P. L. Fernandes, E. M. Rodrigues, F. R. Paiva, B. A. L. Ayupe, M. J. Mcinerney, and M. R. Tótola, "Biosurfactant, solvents and polymer production by Bacillus subtilis RI4914 and their application for enhanced oil recovery," Fuel, vol. 180, pp. 551-557, 2016.

[24] P. K. Gao, H. M. Tian, Y. S Wang et al., "Spatial isolation and environmental factors drive distinct bacterial and archaeal communities in different types of petroleum reservoirs in China," Scientific Reports, vol. 6, no. 1, p. 20174, 2016.

[25] G. Bodtker, I. V. Hvidsten, T. Barth, and T. Torsvik, "Hydrocarbon degradation by Dietzia sp A14101 isolated from an oil reservoir model column," Antonie van Leeuwenhoek, vol. 96, no. 4, pp. 459-469, 2009.

[26] X.-B. Wang, C.-Q. Chi, Y. Nie et al., "Degradation of petroleum hydrocarbons (C6-C40) and crude oil by a novel Dietzia strain," Bioresource Technology, vol. 102, no. 17, pp. 7755-7761, 2011.

[27] T. N. Nazina, E. S. Shumkova, D Sokolova et al., "Identification of hydrocarbon-oxidizing Dietzia bacteria from petroleum reservoirs based on phenotypic properties and analysis of the $16 \mathrm{~S}$ rRNA and gyrB genes," Mikrobiologiia, vol. 84, no. 3, pp. 331-343, 2015.

[28] J. G. Caporaso, C. L. Lauber, W. A. Walters et al., "Global patterns of 16S rRNA diversity at a depth of millions of sequences per sample," Proceedings of the National Academy of Sciences, vol. 108, no. 1, pp. 4516-4522, 2011.

[29] J. G. Caporaso, C. L. Lauber, W. A. Walters et al., "Ultra-highthroughput microbial community analysis on the Illumina HiSeq and MiSeq platforms," The ISME Journal, vol. 6, no. 8, pp. 1621-1624, 2012.

[30] J. G. Gormley, J. Kuczynski, J. Stombaugh et al., "QIIME allows analysis of high-throughput community sequencing data," Nature Methods, vol. 7, no. 5, pp. 335-336, 2010.

[31] R. Bargiela, F. Mapelli, D. Rojo et al., "Bacterial population and biodegradation potential in chronically crude oil-contaminated marine sediments are strongly linked to temperature," Scientific Reports, vol. 5, no. 1, p. 11651, 2015.

[32] T. Magoc and S. L. Salzberg, "FLASH: fast length adjustment of short reads to improve genome assemblies," Bioinformatics, vol. 27, no. 21, pp. 2957-2963, 2011.

[33] R. C. Edgar, "UPARSE: highly accurate OTU sequences from microbial amplicon reads," Nature Methods, vol. 10, no. 10, pp. 996-998, 2013.

[34] S. Winker and C. R. Woese, "A definition of the domains archaea, bacteria and eucarya in terms of small subunit ribosomal RNA characteristics," Systematic and Applied Microbiology, vol. 14, no. 4, pp. 305-310, 1991.

[35] L. Wang, W. Wang, Q. Lai, and Z. Shao, "Gene diversity of CYP153A and AlkB alkane hydroxylases in oil-degrading bacteria isolated from the Atlantic Ocean," Environmental Microbiology, vol. 12, no. 5, pp. 1230-1242, 2010.

[36] M. Kubota, M. Nodate, M. Yasumoto-Hirose et al., "Isolation and functional analysis of cytochrome P450 CYP153A genes from various environments," Bioscience, Biotechnology, and Biochemistry, vol. 69, no. 12, pp. 2421-2430, 2005.

[37] K. Kloos, J. C. Munch, and M. Schloter, "A new method for the detection of alkane-monooxygenase homologous genes 
(alkB) in soils based on PCR-hybridization," Journal of Microbiological Methods, vol. 66, no. 3, pp. 486-496, 2006.

[38] K. Tamura, J. Dudley, M. Nei, and S. Kumar, "MEGA4: molecular evolutionary genetics analysis (MEGA) software version 4.0," Molecular Biology and Evolution, vol. 24, no. 8, pp. 1596-1599, 2007.

[39] N. Saitou and M. Nei, "The neighbor-joining method: a new method for reconstructing phylogenetic trees," Molecular Biology and Evolution, vol. 4, no. 4, pp. 406-425, 1987.

[40] A. Akbari, A. A. Rahim, A. J. Ehrlicher, and S. Ghoshal, "Growth and attachment-facilitated entry of bacteria into submicrometer pores can enhance bioremediation and oil recovery in low-permeability and microporous media," Environmental Science \& Technology Letters, vol. 3, no. 11, pp. 399-403, 2016.

[41] Z. Bihari, Z. Szabo, A. Szvetnik et al., "Characterization of a novel long-chain n-alkane-degrading strain, Dietzia sp E1," Zeitschrift für Naturforschung C, vol. 65, no. 11-12, pp. 693700, 2010.

[42] L. Procópio, V. M. Alvarez, D. A. Jurelevicius et al., "Insight from the draft genome of Dietzia cinnamea P4 reveals mechanisms of survival in complex tropical soil habitats and biotechnology potential," Antonie Van Leeuwenhoek, vol. 101, no. 2, pp. 289-302, 2012.

[43] B. M. Dellagnezze, G. V. de Sousa, L. L. Martins et al., "Bioremediation potential of microorganisms derived from petroleum reservoirs," Marine Pollution Bulletin, vol. 89, no. 1-2, pp. 191-200, 2014.

[44] M. Pannekens, L. Kroll, H. Müller, F. T. Mbow, and R. U. Meckenstock, "Oil reservoirs, an exceptional habitat for microorganisms," New Biotechnology, vol. 49, pp. 1-9, 2019.

[45] Y.-H. She, F. Zhang, J.-J. Xia et al., "Investigation of biosurfactant-producing indigenous microorganisms that enhance residue oil recovery in an oil reservoir after polymer flooding," Applied Biochemistry and Biotechnology, vol. 163, no. 2, pp. 223-234, 2011.

[46] Y. Al-Wahaibi, S. Joshi, S. Al-Bahry, A. Elshafie, A. Al-Bemani, and B. Shibulal, "Biosurfactant production by Bacillus subtilis B30 and its application in enhancing oil recovery," Colloids and Surfaces B: Biointerfaces, vol. 114, pp. 324-333, 2014.

[47] W.-J. Xia, H.-P. Dong, L. Yu, and D.-F. Yu, "Comparative study of biosurfactant produced by microorganisms isolated from formation water of petroleum reservoir," Colloids and Surfaces A: Physicochemical and Engineering Aspects, vol. 392, no. 1, pp. 124-130, 2011.

[48] E. J. Gudiña, J. F. B. Pereira, R. Costa, J. A. P. Coutinho, J. A. Teixeira, and L. R. Rodrigues, "Biosurfactant-producing and oil-degrading Bacillus subtilis strains enhance oil recovery in laboratory sand-pack columns," Journal of Hazardous Materials, vol. 261, pp. 106-113, 2013.

[49] H. Amani, M. M. Müller, C. Syldatk, and R. Hausmann, "Production of microbial rhamnolipid by Pseudomonas aeruginosa MM1011 for ex situ enhanced oil recovery," Applied Biochemistry and Biotechnology, vol. 170, no. 5, pp. 10801093, 2013. 


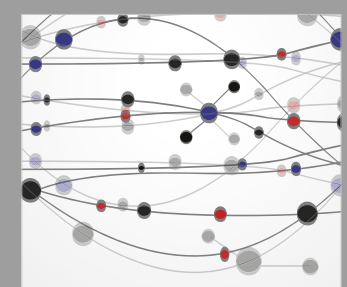

The Scientific World Journal
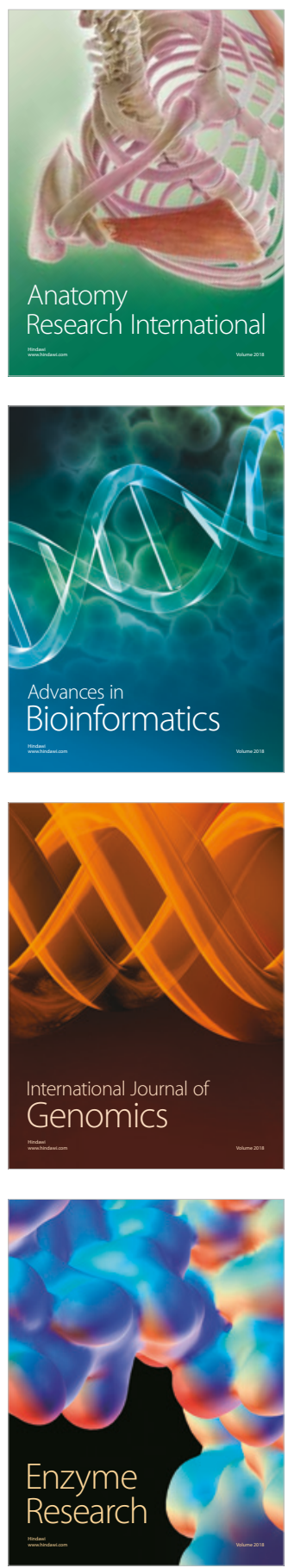
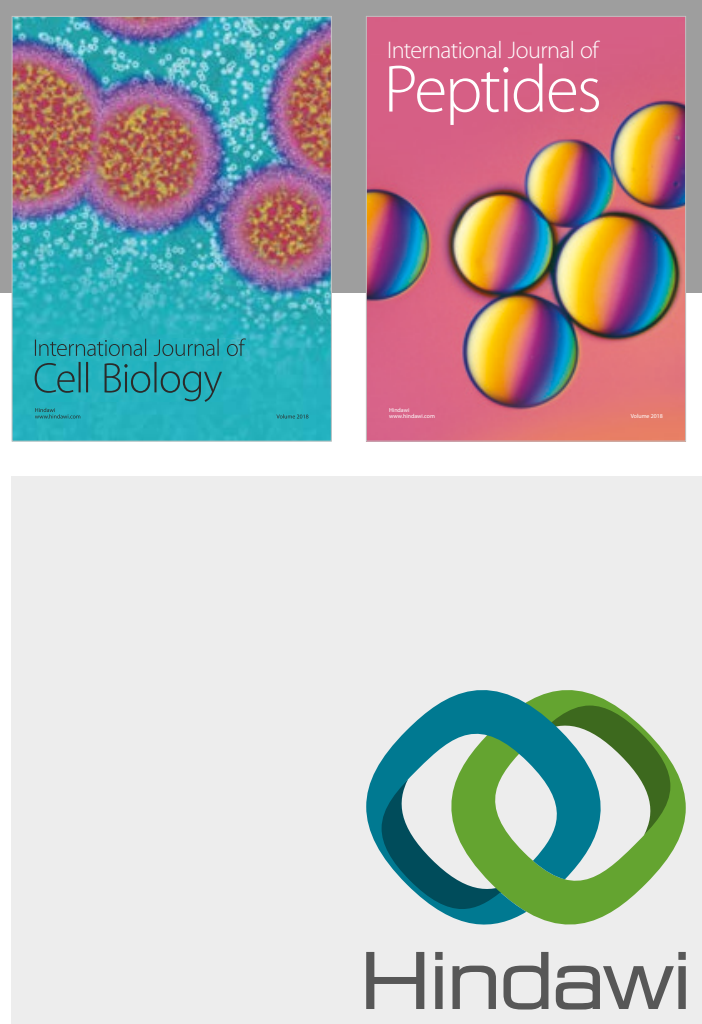

Submit your manuscripts at

www.hindawi.com
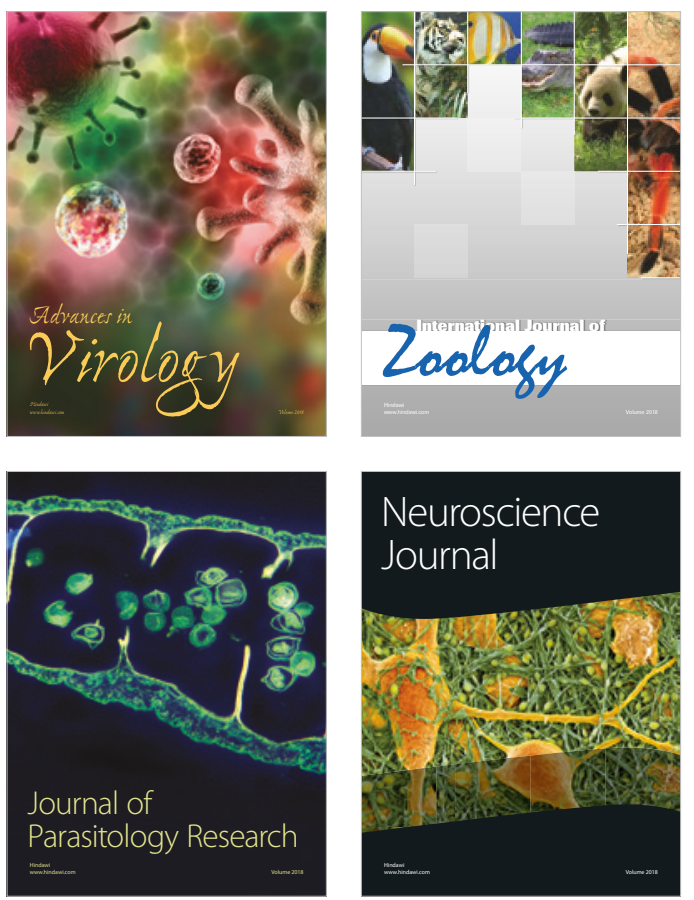
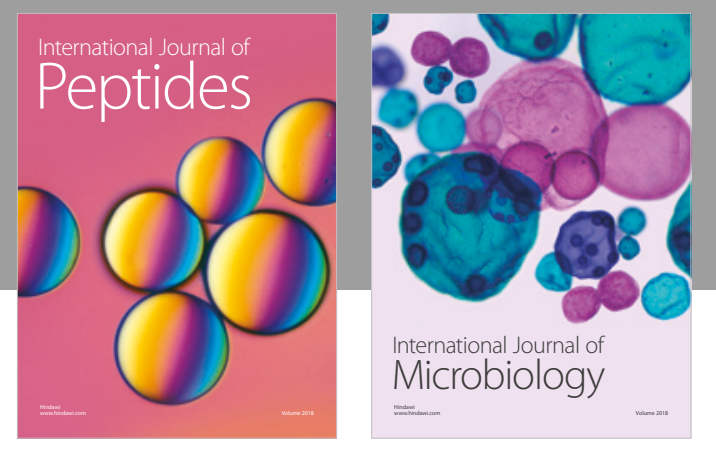

nternational Journal of Microbiology
Journal of
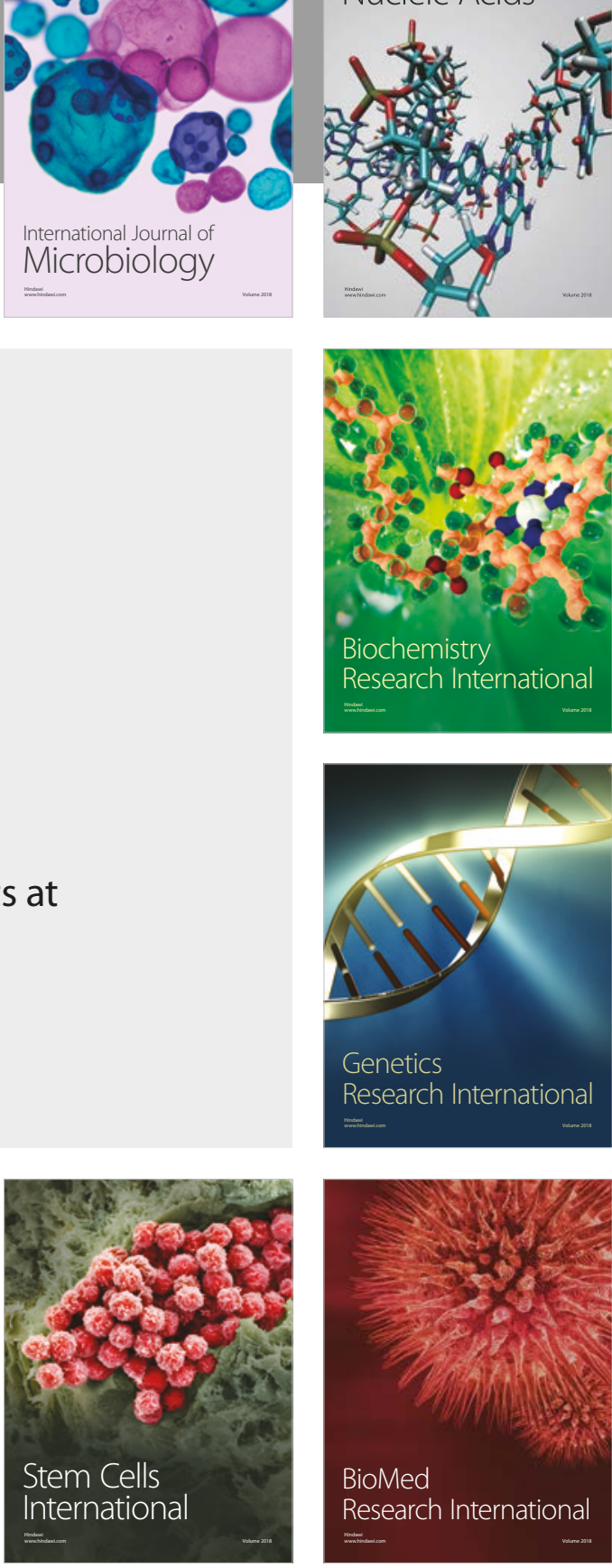
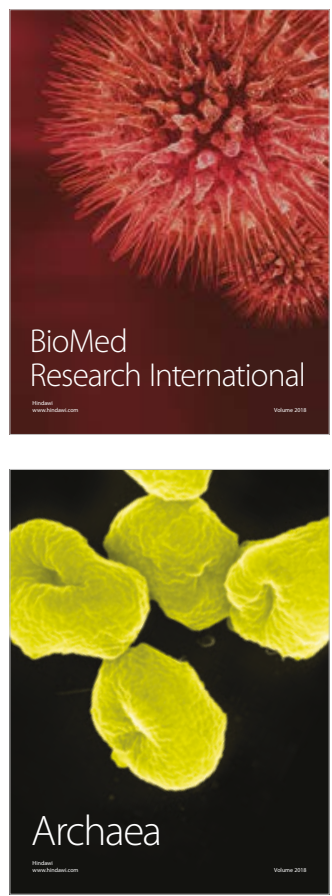